\title{
How Will the Occupation End? A Real-World Exploration of Hindsight Bias and Retroactive Pessimism Concerning Anti-Government Protests in Bulgaria
}

\author{
Nikolay R. Rachev ${ }^{1}$ and Mila Petrova ${ }^{2,3}$ \\ ${ }^{1}$ Department of General, Experimental, Developmental, and Health Psychology, Sofia \\ University St. Kliment Ohridski \\ ${ }^{2}$ Primary Care Unit, Department of Public Health and Primary Care, University of \\ Cambridge \\ ${ }^{3}$ Institute of Public Health, East Forvie Building, Robinson Way, CB2 0SR, Cambridge, \\ UK
}

\section{Author Note}

Nikoay R. Rachev (D) https://orcid.org/0000-0002-5654-2883

Mila Petrova (D) https://orcid.org/0000-0001-7351-6815

Disclosure. We have no conflict of interest to disclose.

Acknowledgements. We are grateful to Mark Pezzo, Hartmut Blank, and Baruch

Fischhoff for their helpful comments on different versions of this manuscript. We also thank N. Rachev's students for their voluntary participation in the study.

Correspondence concerning this article should be addressed to Nikolay R. Rachev, Sofia University St. Kliment Ohridski, 15 Tsar Osvoboditel Blvd., 1504, Sofia, Bulgaria. Email: nrrachev@phls.uni-sofia.bg

Accepted for publication in the American Journal of Psychology. 
HOW WILL THE OCCUPATION END?

\begin{abstract}
We explored hindsight bias and retroactive pessimism related to the occupation of Sofia University in 2013/14, using a memory design. We found partial evidence for hindsight bias for predictions of whether the occupation would achieve its goal (the government's resignation) but not for specific events related to the occupation, which were deemed unlikely from the start and later perceived not to have occurred. We did not find support for retroactive pessimism: hindsight bias indices for the prediction of the government's resignation were not reliably associated with support for the occupation and disappointment with its outcome. We propose using a recall/reconstruct measure as a more rigorous test for retroactive pessimism, which has so far been demonstrated using reassessment.
\end{abstract}

Keywords: hindsight bias, retroactive pessimism, recall, reassessment, real-world events 
HOW WILL THE OCCUPATION END?

\section{How Will the Occupation End? A Real-World Exploration of Hindsight Bias and Retroactive Pessimism Concerning Anti-Government Protests in Bulgaria}

Imagine you were asked to predict how likely it is that the Taliban would regain control of Afghanistan a few weeks before the events of August 2021, and then, a few weeks after them, to recall your predictions. Chances are that your recalled predictions would be higher than your original ones, even though you would not be aware of that. This tendency for people with outcome knowledge to overestimate their ability to predict the outcome in foresight, while denying that outcome information has influenced their judgments, is called hindsight bias (Hawkins \& Hastie, 1990; Roese \& Vohs, 2012). There is, by now, a growing body of evidence that hindsight bias is a reliable and pervasive phenomenon occurring in a wide variety of contexts (for meta-analyses, see Christensen-Szalanski \& Willham, 1991; Guilbault et al., 2004; for theoretical reviews, see Blank et al., 2007; Roese \& Vohs, 2012).

The concept of hindsight bias has a strong intuitive appeal, as people often witness examples of it in others' everyday behaviors (Hawkins \& Hastie, 1990). While the importance of the effect in our everyday lives is also well recognized in the research literature, its real-life occurrence remains underexplored. Of the sizable volume of evidence on hindsight bias collected after the pioneering work of Fischhoff and Beyth (1975), which showed a robust hindsight bias for a range of events during US President Nixon's visit to China and the USSR, relatively little comes from real-world events. As reported by Pezzo and Beckstead (2008), only 21 out of 95 studies in Guilbault et al.'s (2004) meta-analysis involved real-world outcomes and, furthermore, most of those have either used outcomes of little self-relevance to participants or have failed to measure self-relevance. At the same time, real-world situations are far more likely to affect, positively or negatively, individuals' everyday lives than the situations recreated in laboratory 


\section{HOW WILL THE OCCUPATION END?}

experiments and are thus particularly suitable for studying motivational processes hypothesized to underlie hindsight bias for self-relevant outcomes. Accordingly, the present study used a realworld event of high self-relevance to its participants to investigate hindsight bias and its association with a motivation-driven phenomenon, retroactive pessimism (Tykocinski, 2001; Tykocinski et al., 2002).

Retroactive pessimism has been described as a special type of hindsight bias resulting from motivational rather than purely cognitive processing in the face of disappointing outcomes (Tykocinski, 2001; Tykocinski et al., 2002). Presumably, negative outcomes that could have turned out otherwise feel more painful than ones that were "bound to happen", which motivates individuals to perceive disappointing outcomes as unavoidable (Tykocinski, 2001). This is reflected in a retrospective shift of the subjective probabilities for an outcome in a way consistent with the undesirable outcome. Retroactive pessimism is thus driven by the need to cope with disappointing outcomes.

Both studies which introduced the notion of retroactive pessimism (Tykocinski, 2001; Tykocinski et al., 2002) reported supporting evidence from real-life events. In one, voters for the losing candidate for Israeli President, Benyamin Netanyahu, retrospectively increased the chances of victory they had assigned to the winning candidate Ehud Barak to a greater extent than voters for the winning candidate did (but the two groups decreased roughly equally Netanyahu's chances, Tykocinski, 2001, Study 2). In the other, fans of the defeated soccer team retrospectively ascribed higher chances of victory to the winning team and lower ones to the defeated team, with the shift greater than that exhibited by fans of the winning team. The fans of the defeated team also exhibited a correlation of 0.37 between levels of disappointment with the game's outcome and total shifts in their judgments (Tykocinski et al., 2002, Study 1). Findings 
HOW WILL THE OCCUPATION END?

of the latter study have been replicated in a study of a university basketball contest (Wann et al., 2008).

Treating retroactive pessimism as a special type of hindsight bias has been widely accepted (Blank et al., 2008; Roese \& Vohs, 2012). Yet supportive evidence for retroactive pessimism does not come from the original memory design for studying hindsight bias (Pohl, 2007) but, instead, from reassessment. That is, participants are asked to assign a new probability, in light of their outcome knowledge, rather than recall/reconstruct their original prediction (as did Fischhoff \& Beyth, 1975). Retroactive pessimism is deemed to be present if the reassessedrather than recalled - probability is closer to the outcome than the originally assigned probability. This is a small but important deviation from the original definition of hindsight bias (Fischhoff \& Beyth, 1975; see Table 1, rows $1 \& 2$ ).

Inferring hindsight bias from reassessments might be problematic. First, it is unlikely that, if asked to reassess rather than recall a probability, participants are unaware that outcome knowledge has influenced their judgment, which is a defining feature of hindsight bias (Fischhoff, 1975; Hawkins \& Hastie, 1990). Rather, participants might take the researcher's prompt to reassess as an expectation to offer a more realistic assessment, that is, in a direction consistent with the outcome, particularly when they do remember that their original predictions were inaccurate. In addition, from a normative (Bayesian) viewpoint, belief update upon receipt of outcome knowledge is considered optimal behavior rather than a bias (Fischhoff, 1975; Fischhoff \& Beyth, 1975). Reassessed probability can thus be conceived of as a measure of belief update but not of hindsight bias - and has sometimes been used this way. For instance, Fischhoff et al. (2012) asked participants both to recall the probabilities of risk events they had predicted one year earlier and reassess the probabilities of the same events in light of their 
HOW WILL THE OCCUPATION END?

present knowledge. To estimate hindsight bias, Fischhoff et al. then compared participants' original and recalled predictions, using reassessments as the reference point for the comparison, that is, treating them as genuine indices of knowledge update (see Table 1, row 3).

Tykocinski et al. (2002) also considered the possibility that larger probability shifts of the fans of the defeated team might reflect more unrealistic pre-game judgments that need more adjustment. However, they concluded that the correlation between probability shifts and disappointment supports claims about the emotion-driven nature of the observed effect. Further classifying the latter as a subtype of hindsight bias, we argue, is only warranted if verified with a recall as opposed to a reassessment measure of the probability shift.

Ignoring the distinction between findings based on recall versus reassessment might lead to conflating distinct phenomena. For instance, using a recall measure, Pezzo and Beckstead (2008) failed to find evidence for retroactive pessimism among reports of 30 self-relevant events that might occur in everyday life. The inconsistency between these findings and findings demonstrating retroactive pessimism might be at least partially due to the use of different measures which, ultimately, tap into different phenomena.

\section{Table 1}

Three ways of measuring hindsight bias: (1) Recall, using event occurrence as the reference point; (2) Reassessment, using event occurrence as the reference point; (3) Recall, using reassessed probability as the reference point.

\begin{tabular}{llll}
\hline $\begin{array}{l}\text { Probabilities to } \\
\text { compare }\end{array}$ & $\begin{array}{l}\text { Reference } \\
\text { point }\end{array}$ & Hindsight bias is present if: & $\begin{array}{l}\text { Prototypical } \\
\text { Study }\end{array}$ \\
& & & \\
\hline $\begin{array}{l}\text { 1. Original vs. } \\
\text { Recalled }\end{array}$ & Event & a. Recalled > Original AND event occurred & Fischhoff \& \\
& occurrence & b. Recalled < Original AND event not occurred & Beyth (1975)
\end{tabular}


HOW WILL THE OCCUPATION END?

$\begin{array}{ll}\text { 2. Original vs. } & \text { Event } \\ \text { Reassessed } & \text { occurrence }\end{array}$

3. Original vs. Reassessed

Recalled a. Reassessed > Original AND event occurred

b. Reassessed < Original AND event not occurred

a. Recalled > Original AND Reassessed > Original

b. Recalled < Original AND Reassessed < Original
Tykocinski et

al. (2002)

Fischhoff et al. (2005)

Previous research has used memory design to study hindsight bias for self-relevant outcomes almost exclusively outside of the retroactive pessimism framework. Findings have been mixed. In one study, students' recalled predictions of their grades tended to be lower than their original predictions, regardless of whether their predictions were higher or lower than their actual grades. Thus, one group showed hindsight bias after a negative outcome while the other group showed a reverse/negative hindsight bias after a positive outcome (Haslam \& Jayasinghe, 1995). Hindsight bias was also found in individuals who had to recall their predictions about their cholesterol levels immediately after the worrying news that the latter were elevated (Renner, 2003). Several weeks later, however, the same individuals showed a reverse hindsight bias (i.e., their recollected predictions were lower than their actual predictions and were thus even further away from the feedback they received). In the context of political elections, supporters of the losing party showed regular hindsight bias for predictions related to the winning party but a reverse hindsight bias for predictions related to their favorite party, (i.e. they recollected making more positive predictions about their party than their actual predictions, Fischer \& Budescu, 1995). Marketing students playing a market simulation game showed no evidence for hindsight bias for predictions regarding their own performance after a negative outcome although they did so after a positive outcome (Louie et al., 2000). 


\section{HOW WILL THE OCCUPATION END?}

None of the above studies has tested directly for an association between hindsight bias and disappointment, which would have allowed us to consider findings about hindsight bias in self-relevant outcomes from the positions of retroactive pessimism. We are aware of only one study which used a recall measure of hindsight bias and tested for its association with disappointment, namely, Blank and Nestler (2006) who reported a correlation of -.40 between a recall measure of hindsight bias and disappointment regarding the outcome of Leipzig's candidacy for the Olympics. The direction of the association is opposite to that predicted by the theoretical framework of retroactive pessimism. However, the prediction measure used was binary (Leipzig will vs. will not be nominated) and only 9 out of 101 recollections were incorrect. There is thus a significant uncertainty in interpreting the reported association.

Given the fragmentary and inconsistent nature of previous findings, we aimed to test for retroactive pessimism as a subtype of hindsight bias using memory design, which offers a far more stringent test than reassessment for detecting a bias as opposed to detecting a belief update. The target event underpinning the study offered a rare opportunity to explore the phenomenon amongst people deeply invested in a situation, making its outcomes highly self-relevant. It was also an infrequent occasion when students were a highly suitable group of participants conceptually, not only pragmatically.

\section{Target Event}

The event used for this study was the occupation of Sofia University, the oldest university in Bulgaria, in 2013. The occupation caused a radical disruption to everyday academic routines, making it a unique situation where all students and faculty were involved, whether 
HOW WILL THE OCCUPATION END?

voluntary or not. It was thus an event of high personal relevance to our participants, who were students in the university. Below are some details of the occupation.

On October 23, 2013, four months into massive civil protests against the Bulgarian Government, a group of students occupied the largest auditorium of the Sofia University Rectorate, the main university building. Two days later the occupiers declared full occupation of the Rectorate and demanded the Government's resignation. In the following three months they initiated a variety of activities, including banner displays and workshops discussing their course of action before and after the demanded resignation. The occupation movement spread to other Bulgarian universities, but there it was weaker and soon died away. The administration of Sofia University did not officially support the protests, yet a declaration in support of the student occupiers was signed, allegedly, by more than 600 Bulgarian professors (Junes, 2013). Students were also divided. Opponents of the occupation argued that it was an ill-chosen strategy to protest that was supported by a small minority of students (although it is known that dozens of students took part in the occupation, official numbers have not been reported). Finally, on January 14, 2014, the occupying students declared the end of the occupation, with the argument that it had been exhausted as a form of protest and could not achieve its main goal. They promised to continue their protest in other ways, such as through workshops and informal networks, but their subsequent activities were rarely reported by the media. Overall, the occupation did not achieve its main goal, with the government not resigning until July 23, 2014, six months after the end of the occupation. 
HOW WILL THE OCCUPATION END?

\section{Overview of the Present Study}

We asked participants to judge the probability of a range of events related to the occupation occurring while it was underway. After its end, we asked them to recall their probability judgments and state if they think the events in question have occurred or not. We thus studied hindsight bias using a memory design (Pohl, 2007), with time point (before and after the events) varying within participants and event occurrence varying between participants. As in previous research using real-life events (Fischhoff \& Beyth, 1975; Pezzo \& Beckstead, 2008), event occurrence was determined by the participants rather than the researchers. We expected that, relative to the original predictions, the recalled predictions would be higher for events perceived to have occurred and lower for events perceived not to have occurred, thus providing evidence for hindsight bias. To test for retroactive pessimism, we tested whether the size of the hindsight bias concerning the overall outcome of the occupation would be associated with ratings of support for the occupation and disappointment with its outcome, similarly to studies that used, however, a reassessment measure (Tykocinski, 2001; Tykocinski et al., 2002). ${ }^{1}$

1 The study also had two additional exploratory aspects. First, we explored the spontaneous generation of counterfactuals, following Roese and Olson (1996). However, the items we devised turned out to be ineffective for their original purpose and were, in effect, close correlates to ratings of support for the occupation. We also collected participants' attributions of responsibility to the occupiers concerning a list of potential accidents. We were interested whether we would find, in the case of an incident, an association between recalled probability and recalled attributions of responsibility similar to the association between assigned probability and responsibility in between-subjects research using written scenarios (Hastie et al., 1999). However, none of the target incidents occurred. An English version of the Part 2 survey including all items is available at https://osf.io/zrjht/?view_only=d7cea9e0351b4f2694cacb835bbd9a5d 
HOW WILL THE OCCUPATION END?

\section{Method}

\section{Participants}

Fifty-eight psychology undergraduates participated in Part 1, and 47 in Part 2. All participants were students at the occupied university, attending one of two courses on its Psychology Bachelors' Program. Participation was voluntary, without payment or course credits attached to it. Thirty participants filled in both parts, but data were successfully matched for 29 participants (all Bulgarian, 24 female, 5 male, mean age at Part $2=19.97, S D=1.80$ ). Given our focus on memory design, we present the analyses for the latter sample. The data and code for reproducing the analyses are available at https://osf.io/zrjht/?view_only=d7cea9e0351b4f2694cacb835bbd9a5d.

\section{Materials and Procedure}

In each part, participants filled in an anonymous online survey. In Part 1, participants first made their predictions regarding the outcome of the occupation. The outcome was represented through a composite item linking three possible developments for the occupation (end; continue; transform into another form of protest) to the achievement or failure of its ultimate goal (the government resigns or does not resign). The resulting options (mutually exclusive) were as follows:

(a) The Government will resign; the occupation will end;

(b) The Government will resign; the occupation will NOT end;

(c) The Government will NOT resign; the occupation will NOT end; 
HOW WILL THE OCCUPATION END?

(d) The Government will NOT resign; the occupation will end; the students will launch another form of protest;

(e) The Government will NOT resign; the occupation will end; the students will NOT launch another form of protest.

Hereafter we refer to the above composite item as a "general outcome item". It was repeated twice, asking for predictions (1) in three months' time and (2) with respect to the final outcome. The probabilities assigned to the five options had to sum up to 100 percent.

Participants also judged the likelihood of five specific events to occur in the following three months as a direct result of the occupation: two incidents (a property-related incident in the university building and a violent clash between occupiers and their opponents), two types of externally driven termination of the occupation (by force or by political intervention), and a nonpolitical consequence (the academic year being declared void). These items are hereafter referred to as specific-event prediction items. ${ }^{2}$

After making their predictions, participants rated their familiarity with the target event by reporting their agreement with the statement 'I am familiar with the occupation story' $(1=$ 'completely disagree', $10=$ 'completely agree') and their reliance on the written description provided at the start of the questionnaire versus reliance on their own knowledge about the situation $(1=$ complete reliance on the description; $9=$ complete reliance on personal knowledge). Subsequently, participants indicated their agreement, on a 10-point scale $(1=$

2 The prediction items also included a numerical prediction as to the number of days until 'a final resolution of the situation' is reached and an open-ended prediction as to what would happen in the following three months (see online supplementary materials). These items are not included in the analyses, since the former was later deemed to be framed too vaguely and the latter was included for exploratory purposes only. 
HOW WILL THE OCCUPATION END?

'completely disagree', $10=$ 'completely agree'), with the statements 'I support the protests against the Government' and 'I support the occupation'. Finally, they noted their gender, age, and course type and provided an anonymous code to enable the matching of their Part 1 and Part 2 responses.

In Part 2, participants were asked to do their best to recall their original predictions. Following Fischhoff and Beyth (1975), the order of the prediction items and item options was changed from Part 1 to prevent the effect of incidental verbatim memorization related to the item's position in the series. Participants then rated their familiarity with the occupation story and with the occupation outcome using the same 10-point scale as in Part 1. Following Fischhoff and Beyth (1975) again, participants indicated whether they perceived relevant events to have occurred or not. They had to pick one of the five options of the general-outcome predictions (linking the occupation activity and the government resignation) as the final outcome of the occupation $^{3}$ and choose "yes" or "no" to indicate whether they believed that any of the five specific events (violent clash between occupiers and non-occupiers, termination by political intervention, etc.) had happened or not. Subsequently, participants rated their support for the protests and for the occupation on the same items as used in Part 1. They also indicated how they felt about the outcome of the occupation $(1=$ highly disappointed; $7=$ highly satisfied $)$. These scores were reversed in the analyses so that higher scores denoted greater disappointment. Finally, participants filled in the same demographic information as in Part 1. All materials were in Bulgarian. An English translation of the Part 2 questionnaire is available at https://osf.io/zrjht/?view_only=d7cea9e0351b4f2694cacb835bbd9a5d.

3 As it turned out, the occupation lasted approximately three months, so there was no need for a separate question asking about the perceived state of affairs after three months. 
HOW WILL THE OCCUPATION END?

Participants were reached through their online course pages. Part 1 was open between November 9 (approximately two weeks after the start of the occupation) and November 18, 2013. Part 2 opened on February 7, 2014, a week after the end of a brief second occupation. Twenty participants who had participated in Part 1 responded within approximately a week (average time between completion of Part 1 and Part 2 questionnaires was 88 days). At the beginning of March 2014, a reminder letter was sent to Part 1 participants, after which nine questionnaires were completed (average time between Part 1 and Part 2 was 121 days). No association between hindsight bias indices and the timing of responses was found, so participants are reported as a single group throughout.

\section{Calculation of Variables and Analysis Considerations}

\section{Hindsight Bias}

Hindsight Bias Measure. Hindsight bias was operationalized as recalled minus original prediction for events perceived to have occurred, and original minus recalled prediction for events perceived not to have occurred. Pohl (2007) called this "absolute hindsight bias index" and recommended it for use in hindsight bias research with categorical outcomes (such as occurred/not occurred). For the general-outcome items, responses where the sum of the five options was not equal to 100 were rescaled $^{4}$ to sum up to 100.

Testing for Hindsight Bias. Not all of the options in the general-outcome items were used to test for hindsight bias. Option (b), 'government resigned and occupation not ended', was

4 Given the small sample, we wanted to keep these observations (nine for the three-month prediction and eight for the final outcome prediction). Rescaling was done by dividing the original value by the sum of the five options and multiplying by 100 . 
HOW WILL THE OCCUPATION END?

included in the set so as to exhaust all possible combinations, but is clearly artificial relative to the original goals of the occupation. Option (c), 'government not resigned and occupation not ended', was also excluded, since it would be a sensible prediction for the three-month outcome but not for the final outcome. For the sake of completeness, descriptive statistics for these options are still provided (see Table 3 ). We tested for hindsight bias by performing $11 t$-tests overall (on options [a], [d], and [e] of each of the two general-outcome items and on the five specific event items), rather than averaging at a higher level, such as general and specific outcomes. ${ }^{5}$ This allowed us to test whether hindsight bias was consistently present or absent across the items. To control for false discovery rate, we performed Benjamini-Hochberg correction on the $p$-values (Benjamini \& Hochberg, 1995).

Optimizing Type I Error in Testing for Hindsight Bias. Based on previous metaanalyses (Christensen-Szalanski \& Willham, 1991; Guilbault et al., 2004), the value of Cohen's $d=0.39$ was taken as an average effect size of hindsight bias for real-life events. Power analyses showed that, with a sample of 29 participants, using the conventional Type I error level of .05 would result in statistical power of .66 for a one-tailed $t$-test. Since such low power is undesirable, we followed recommendations for optimizing alpha levels by minimizing the combined (average) probability of making Type I and Type II error for a study with a given sample size, after the data have been collected (Mudge et al., 2012). Using an R-code available for this purpose (Mudge et al., 2017), we estimated that, given the sample size and the a priori effect size of $d=0.39$, the minimum combined probability of making either Type I or Type II error would be equal to .149 , still leaving room for a substantially higher probability of making a

5 This decision was further justified by the low correlations among some of the individual hindsight bias indices, leading to low internal consistency of the combined scales (see Musch \& Wagner, 2007). 
HOW WILL THE OCCUPATION END?

correct conclusion (.851). This minimum combined probability would be achieved by setting the Type I error level to .153 and the Type II error level to .145, leading to statistical power of .855 .

\section{Retroactive Pessimism}

Retroactive Pessimism Measure. Following Tykocinski et al. (2002), evidence for retroactive pessimism was judged by the size of correlations between the hindsight bias indices for the relevant prediction items, on the one hand, and the ratings of support for the occupation (in Part 1 and Part 2) and disappointment with its outcome, on the other.

Testing for Retroactive Pessimism. A necessary condition for retroactive pessimism is that a disappointing (i.e., negative) event occurs or a desirable (positive) event fails to occur. The general-outcome items, referring to the unachieved government's resignation, contained such potentially disappointing outcomes, from the perspective of supporters of the occupation.

However, two of the options referring to the government not resigning ( $\mathrm{d}$ and e) did not meet the above-mentioned condition. Whether the state of affairs they were describing occurred or not was not unanimously agreed upon. Hence, it was impossible to assign a positive or negative value to these events from a supporter's perspective. Therefore, to test for retroactive pessimism, we correlated support variables only to option (a), 'government resigned and occupation ended'. This was a desirable event, from a supporter's perspective, that has clearly not occurred. In line with previous results (Tykocinski et al., 2002; Wann et al., 2008), we hypothesized that higher disappointment would be related to larger hindsight bias indices concerning option (a). We further tested if hindsight bias indices concerning option (a) would correlate with reported support for the occupation in Parts 1 and 2. Six correlation coefficients were thus calculated from linking option (a), in each of the two general-outcome items, to the three support and 
HOW WILL THE OCCUPATION END?

disappointment items. To control for false discovery rate, we performed the Benjamini-Hochberg correction.

Optimizing Type I Error in Testing for Retroactive Pessimism. We took the value of .37 , the reported Pearson correlation between a shift in prediction and disappointment (Tykocinski et al., 2002), as the expected effect size. Power analyses showed that, with 29 participants, using the conventional Type I error level of .05 would result in statistical power of .64 for a one-tailed test. The optimized alpha approach (Mudge et al., 2012, 2017) showed that the minimum combined probability of making either Type I or Type II error was .218, achieved by setting the Type I error level to .183 and the Type II error level to .253, that is, statistical power of .747. Given the increased power, we used the optimized alpha approach in testing for retroactive optimism, as we did in testing for hindsight bias. Since power estimations for retroactive pessimism were based on a Pearson product-moment correlation coefficient, we used this type of coefficient throughout the analyses, despite its sensitivity to outliers, which may be highly influential in small samples. Analyses using a more robust measure of association (e.g. Kendall Tau) led to identical results.

For both hindsight bias and retroactive pessimism, we also calculated Bayes factors (BF) to estimate the likelihood of the alternative hypotheses relative to the null (Ly et al., 2016; Morey \& Rouder, 2011; Rouder et al., 2009). The effect sizes of $d=0.39$ for hindsight bias and $r=0.37$ for retroactive pessimism were used as informed alternative hypotheses. All analyses were made using R, version 4.1.0 (R Core Team, 2021), and the following packages: MAd (Hoyt, 2018), compute.es (Re, 2020), pwr (Champely, 2018), tidyverse (Wickham \& RStudio, 2019), psych (Revelle, 2020), sgof (Conde \& de Una Alvarez, 2016), BayesFactor (Morey et al., 2018), and gridExtra (Auguie, 2017). 
HOW WILL THE OCCUPATION END?

\section{Results}

Familiarity, support, and disappointment ratings are presented in Table 2. Overall, participants were highly familiar with the event and reported high support for the protests in general but were more ambivalent towards the occupation, as shown by both support and disappointment ratings. All participants agreed that the government had not resigned and the occupation had ended, but while 20 participants believed that the occupiers had launched another form of protest, nine believed they had not (see Table 3$).{ }^{6}$ The specific events were largely perceived not to have occurred: this was the case in 125 out of 145 responses, and no event had more than nine 'occurred' responses (see Table 4).

\section{Table 2}

Familiarity, support, and disappointment ratings

\begin{tabular}{|c|c|c|c|c|c|}
\hline \multirow[b]{2}{*}{ Variable } & \multirow[b]{2}{*}{$\begin{array}{l}\text { Potential } \\
\text { Minimum- } \\
\text { Maximum }\end{array}$} & \multicolumn{2}{|c|}{ Part 1} & \multicolumn{2}{|c|}{ Part 2} \\
\hline & & $M(S D)$ & $\begin{array}{l}\text { Observed } \\
\text { Minimum- } \\
\text { Maximum }\end{array}$ & $M(S D)$ & $\begin{array}{l}\text { Observed } \\
\text { Minimum- } \\
\text { Maximum }\end{array}$ \\
\hline $\begin{array}{l}\text { Familiarity with the occupation } \\
\text { story }\end{array}$ & $1-10$ & $8.72(1.98)$ & $1-10$ & $8.90(1.18)$ & $6-10$ \\
\hline $\begin{array}{l}\text { Reliance on personal knowledge } \\
\text { vs. written description }\end{array}$ & $1-9$ & $7.45(1.82)$ & $3-9$ & -- & -- \\
\hline $\begin{array}{l}\text { Familiarity with the occupation } \\
\text { outcome }\end{array}$ & $1-10$ & -- & -- & $7.76(2.40)$ & $3-10$ \\
\hline Support for the protests & $1-10$ & $8.14(2.01)$ & $2-10$ & $8.72(1.39)$ & $6-10$ \\
\hline Support for the occupation & $1-10$ & $5.21(3.00)$ & $1-10$ & $5.83(3.19)$ & $1-10$ \\
\hline $\begin{array}{l}\text { Disappointment with the } \\
\text { occupation outcome }\end{array}$ & $1-7$ & -- & -- & $4.07(1.77)$ & $1-7$ \\
\hline
\end{tabular}

6 This disagreement was understandable, since the occupiers' actions after the end of the occupation did not receive much media coverage. 
HOW WILL THE OCCUPATION END?

Note. Higher numbers denote higher familiarity, support, or disappointment.

\section{Hindsight Bias}

\section{General-Outcome Predictions}

Detailed results concerning general-outcome predictions are presented in Table 3 . The hindsight bias index for the option 'government resigned and occupation ended' (option a) at three months was of a moderate size and statistically significant, $d=0.54, t(28)=2.91, p_{\text {adjusted }}=$ .04. The Bayes Factor showed that the observed effect is 13 times more consistent with a distribution centered at the expected effect size (alternative hypothesis) than with no effect (null hypothesis). The index for the same option for the final outcome prediction was in the expected direction but small in size and not statistically significant. This was also the case for the 'government not resigned, occupation ended, no new protest' (e), final-outcome prediction. The Bayes factors of the latter two indices were roughly equally consistent with both the null and alternative hypothesis (ratios less than 2:1 in either direction). The remaining three hindsight bias indices (for option e, three months, and option d, three months and final outcome) were of negligible size and statistically not significant. The Bayes factors showed that their observed effects are more likely under the null than under the alternative hypothesis by a ratio of 2.5:1 or more. 
HOW WILL THE OCCUPATION END?

Table 3

General-outcome predictions: Perceived occurrence (PO), original (Part 1) and recalled (Part 2) predictions: means (and standard deviations), hindsight bias (HSB) indices: means (standard deviations), Benjamini-Hochberg-adjusted p-values from t-tests for HSB indices, Cohen's ds, and Bayes Factors (BF).

\begin{tabular}{ccccccccc}
\hline Item / Option & PO & $\mathrm{N}$ & Part 1 & Part 2 & HSB index & p.adj & $a$ & $B F_{10}$ \\
\hline
\end{tabular}

In three months:

Government resigned
(a) + Occupation Ended
No $\quad 29 \quad \begin{array}{rrr}25.05 & 15.60 \\ (18.62) & (13.80)\end{array}$
9.45
$(17.45)$
$.04 \quad 0.54 \quad 13.42$
(b) + Occupation Not Ended

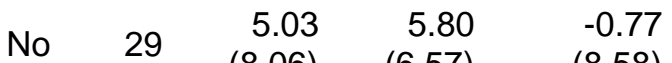
$\begin{array}{rrr}5.03 & 5.80 & -0.77 \\ (8.06) & (6.57) & (8.58)\end{array}$

Government Did Not Resign

(c) + Occupation Did Not End

$\begin{array}{lrrrrrrr}\text { No } & 29 & 18.20 & 21.37 & -3.17 & & & \\ & & (13.69) & (17.72) & (22.64) & & & \\ \text { Yes } & 20 & 40.75 & 39.21 & & & & \\ & & (13.87) & (15.90) & 0.28 & .74 & 0.01 & 0.34 \\ \text { No } & 9 & 27.41 & 23.07 & (19.52) & & & \\ & & (13.96) & (14.89) & & & & \\ \text { Yes } & 9 & 21.56 & 35.80 & & & & \\ & & (14.28) & (18.30) & 0.92 & .73 & 0.05 & 0.39 \\ \text { No } & 20 & 12.22 & 17.29 & (19.63) & & & \end{array}$

Final Outcome:

Government resigned
(a) + Occupation Ended
No
$29 \quad \begin{array}{rr}28.79 & 21.47 \\ (23.56) & (17.56)\end{array}$
7.33
(23.54)
.26
0.31
1.74
(b) + Occupation Not Ended

$\begin{array}{lll}4.01 & 3.33 & 0.68\end{array}$
$\begin{array}{lrrrr}\text { No } & 29 & 4.01 & 3.33 & 0.68 \\ & & (7.90) & (3.92) & (7.02)\end{array}$

Government Did Not Resign

(c) + Occupation Did Not End

No $\quad 29 \quad \begin{array}{rr}15.41 & 18.93 \\ (16.71) & (16.38)\end{array}$

$-3.52$

$\begin{array}{lrrr}\text { Yes } & 20 & 40.64 & 36.85 \\ & & (17.35) & (21.42)\end{array}$

(d) + Occupation Ended

+ New Protest

$\begin{array}{llrr}\text { No } & 9 & 31.25 & 27.41 \\ & & (18.50) & (14.87)\end{array}$

$-1.42$

$(24.76)$

$\begin{array}{lll}\text { Yes } \quad 9 & 18.11 \quad 37.96\end{array}$

(e) + Occupation Ended

15.15) (7.26)

No $20 \quad 12.24 \quad 15.33$

4.03

$\begin{array}{lll}.34 & 0.22 \quad 0.95\end{array}$

(9.58) (9.82) 
HOW WILL THE OCCUPATION END?

\section{Specific-Event Predictions}

Results for specific-event predictions are presented in Table 4. All hindsight bias indices were of negligible to small size, and three out of five were in the opposite to the expected direction. The Bayes factors showed that those three were more likely under the null than under the alternative hypothesis by a ratio of 3.3:1 or more, and the remaining two were roughly equally consistent with both the null and alternative hypotheses. Notably, original predictions were on average quite low, particularly in the vast majority of cases where events were later perceived not to have occurred. Figure 1 shows that, in line with Fischhoff and Beyth's (1975) findings, for events perceived not to have occurred, median reconstructed values tended to be lower than the original for all but the smallest original values (i.e. values lower than 20\%). That is, the findings are consistent with hindsight bias for original values higher than 20 . However, as the lower panel of Figure 1 shows, about two-thirds of the original values (82 of 125) were in the [0-20] range, thus limiting the possibility for detecting hindsight bias. Although based on much fewer data points, a similar tendency was observed for events perceived to have occurred, where eight out of 20 (i.e., 40\%) of the original predictions were in the [75-90] range, thus limiting the possibility for even higher recalled predictions. 
HOW WILL THE OCCUPATION END?

Table 4

Specific-event predictions: Perceived occurrence (PO), original (Part 1) and recalled (Part 2) predictions: means (and standard deviations), hindsight bias (HSB) indices: means (standard deviations), BenjaminiHochberg-adjusted p-values from t-tests for HSB indices, Cohen's ds, and Bayes Factors (BF).

\begin{tabular}{|c|c|c|c|c|c|c|c|c|}
\hline \multirow{2}{*}{$\begin{array}{l}\text { Item } \\
\text { House-keeping accident }\end{array}$} & \multirow{2}{*}{$\begin{array}{l}\mathrm{PO} \\
\text { No }\end{array}$} & \multirow{2}{*}{$\frac{N}{29}$} & \multirow{2}{*}{$\begin{array}{r}\text { Part 1 } \\
13.59 \\
(17.36)\end{array}$} & \multicolumn{2}{|c|}{ Part 2 HSB index } & \multirow{2}{*}{$\begin{array}{r}\text { p.adj } \\
.87\end{array}$} & \multirow{2}{*}{$\begin{array}{r}d \\
-0.22\end{array}$} & \multirow{2}{*}{$\begin{array}{l}B F_{10} \\
0.17\end{array}$} \\
\hline & & & & $\begin{array}{r}17.31 \\
(20.70)\end{array}$ & $\begin{array}{r}-3.72 \\
(17.26)\end{array}$ & & & \\
\hline \multirow[t]{2}{*}{ Violent clash } & No & 20 & $\begin{array}{r}32.25 \\
(23.53)\end{array}$ & $\begin{array}{r}26.00 \\
(14.92)\end{array}$ & $\begin{array}{r}4.83 \\
(17.24)\end{array}$ & .26 & 0.28 & 1.40 \\
\hline & Yes & 9 & $\begin{array}{r}46.67 \\
(26.93)\end{array}$ & $\begin{array}{r}48.33 \\
(31.52)\end{array}$ & & & & \\
\hline \multirow[t]{2}{*}{ Termination by force } & No & 21 & $\begin{array}{r}28.19 \\
(24.50)\end{array}$ & $\begin{array}{r}21.43 \\
(16.59)\end{array}$ & $\begin{array}{r}-0.52 \\
(29.27)\end{array}$ & .74 & -0.02 & 0.30 \\
\hline & Yes & 8 & $\begin{array}{r}66.50 \\
(27.82)\end{array}$ & $\begin{array}{r}46.88 \\
(23.75)\end{array}$ & & & & \\
\hline \multirow[t]{2}{*}{ Termination by politics } & No & 26 & $\begin{array}{r}18.50 \\
(19.59)\end{array}$ & $\begin{array}{r}24.23 \\
(18.31)\end{array}$ & $\begin{array}{r}-3.93 \\
(25.52)\end{array}$ & .87 & -0.15 & 0.20 \\
\hline & Yes & 3 & $\begin{array}{r}50.00 \\
(21.79)\end{array}$ & $\begin{array}{r}61.67 \\
(16.07)\end{array}$ & & & & \\
\hline Academic year void & No & 29 & $\begin{array}{r}19.66 \\
(24.58)\end{array}$ & $\begin{array}{r}16.55 \\
(20.18)\end{array}$ & $\begin{array}{r}3.10 \\
(20.43)\end{array}$ & .46 & 0.15 & 0.64 \\
\hline
\end{tabular}


HOW WILL THE OCCUPATION END?

Figure 1.

Specific-event predictions: Distributions (boxplots) of recalled probabilities for events assigned an original probability of $X \%$ (upper panel), plotted against the frequency distribution (histogram) of the before probabilities (lower panel). Separate plots for events perceived not to have occurred (left) and events perceived to have occurred (right).
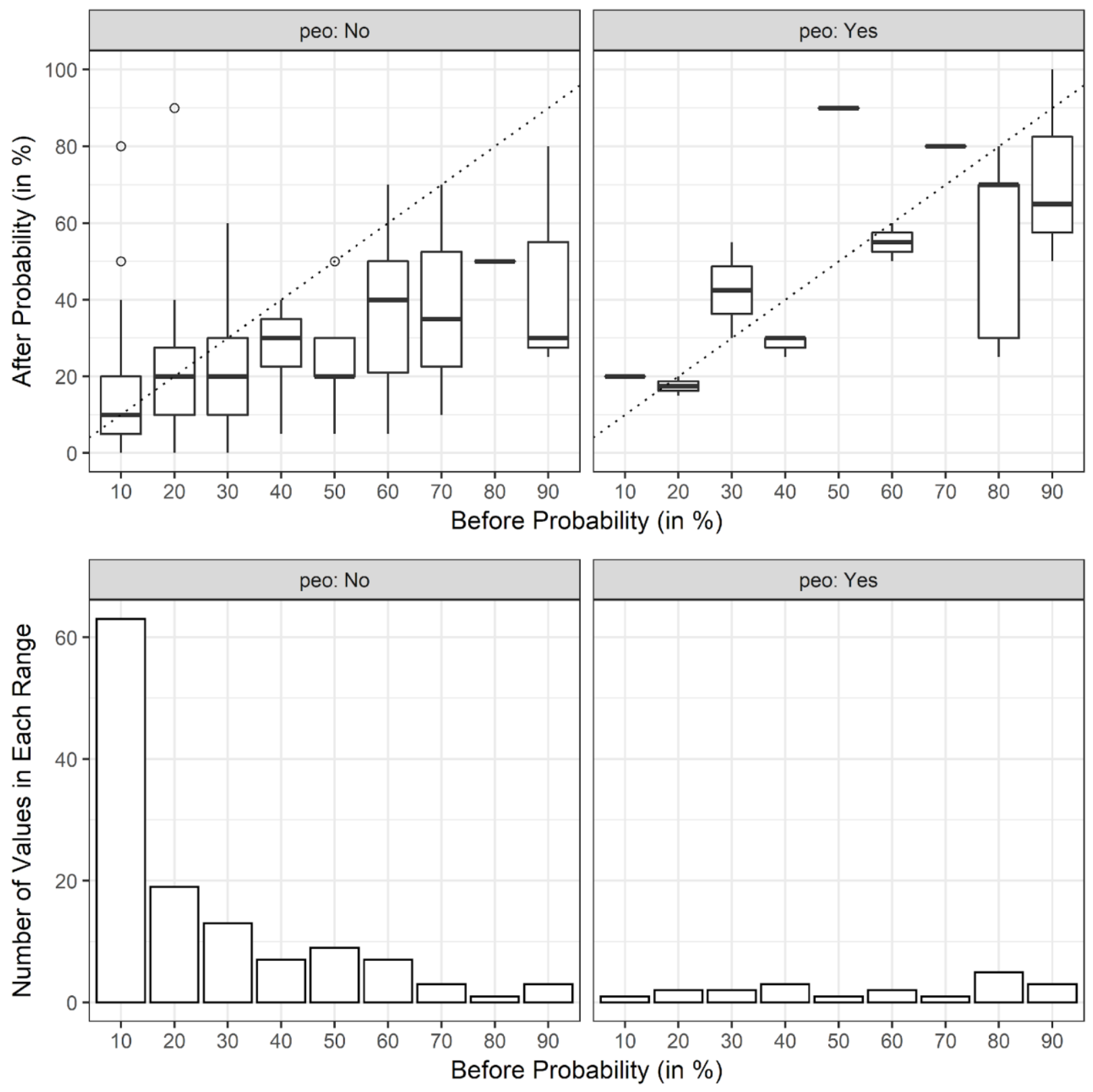

Note . peo $=$ perceived event occurrence. Horizontal thick lines of the individual boxplots denote medians. 
HOW WILL THE OCCUPATION END?

\section{Retroactive Pessimism}

Neither disappointment with the occupation outcome, nor support for the occupation correlated significantly with hindsight bias indices for the 'government resigned, occupation ended' option of the two general-outcome items (Table 5). Bayes factors showed that two of the observed effects were roughly equally consistent with the hypothesized effect and the null hypothesis of no effect. The remaining four were more consistent with the null by a ratio of 2:1 or more.

Further exploration showed that participants' predictions tended to be consistent with their ratings of support for the occupation at Part 1 for both the general-outcome and specificevent predictions (Table 6). Participants appeared to be making predictions in line with their desired outcomes, suggesting some form of motivational processing in Part 1 which, however, did not translate into detectable retroactive pessimism in Part 2.

\section{Table 5}

Hindsight bias indices for the 'government resigned, occupation ended' prediction and motivational items: Pearson product-moment correlations ( $r)$, $p$-values adjusted using Benjamin-Hochberg correction ( $p_{\text {adj }}$ ), and Bayes Factors (BF)

\begin{tabular}{llccc}
\hline HSB index & motivational item & $r$ & $p_{\text {adj }}$ & $B F_{10}$ \\
\hline $\begin{array}{l}\text { Government resigned, occupation ended } \\
\text { (3 months) }\end{array}$ & Disappointment & .19 & .53 & 0.98 \\
& Support Part 1 & .18 & .53 & 0.90 \\
& Support Part 2 & .05 & .78 & 0.47 \\
& Disappointment & -.06 & .78 & 0.32 \\
$\begin{array}{l}\text { Government resigned, occupation ended } \\
\text { (final outcome) }\end{array}$ & Support Part 1 & -.08 & .78 & 0.29 \\
& Support Part 2 & -.15 & .78 & 0.24 \\
\hline
\end{tabular}


HOW WILL THE OCCUPATION END?

Table 6

Correlations between Part 1 predictions and support for the occupation

Correlation with support

\begin{tabular}{lr} 
Prediction & for the occupation \\
\hline In three months: & .34 \\
Government resigned + Occupation Ended (a) & -.10 \\
Government Did Not Resign + Occupation Ended + New Protest (d) & -.54 \\
Government Did Not Resign + Occupation Ended + No New Protest (e) & .29 \\
Final Outcome: & -.07 \\
$\quad$ Government resigned + Occupation Ended (a) & -.36 \\
Government Did Not Resign + Occupation Ended + New Protest (d) & -.39 \\
Government Did Not Resign + Occupation Ended + No New Protest (e) & -.47 \\
House-keeping accident & -.14 \\
Violent clash & -.14 \\
Termination by force & -.32 \\
Termination by politics & \\
Academic year void &
\end{tabular}

\section{Discussion}

We used a memory design to test for hindsight bias and retroactive pessimism with respect to a salient and highly charged political event in Bulgaria, the occupation of Sofia University, whose ultimate (and unachieved) goal was the resignation of the government. Participants were highly involved in the event, being students at the University. They had to make predictions about two items related to the occupation's main goal (the government's resignation) and about five specific events related to the occupation. Hindsight bias was found 
HOW WILL THE OCCUPATION END?

for the prediction that the government would resign and the occupation would end within three months. This was an event unanimously perceived not to have occurred, recalled probabilities for which were consistently lower than the original. A similar, although statistically non-significant, tendency was found for the same prediction concerning the final outcome. There was no evidence for hindsight bias regarding predictions that the government would not resign, the occupation would end, and there would or would not be another form of protest. The failure to detect hindsight bias for these predictions could, potentially, be due in part to their complexity. Namely, participants had to judge the joint probability of three events (government not resigned, occupation ended, and new protests/no new protests launched). This may have posed a significant challenge not only in terms of formulating a prediction and recalling it but also in terms of judging occurrence and non-occurrence, particularly since there was no consensus whether the occupiers had actually launched new protests.

No evidence was found for hindsight bias concerning the specific events; in fact, evidence from Bayes factors was more consistent with a lack than with a presence of hindsight bias. Exploratory analyses showed that although there was evidence consistent with hindsight bias for original values larger than $20 \%$, this tendency was overshadowed by the fact that most participants judged the specific events to be highly unlikely at Part 1 and perceived them as not having occurred at Part 2. Low original predictions for non-occurrences naturally prevent recalling even lower estimates, leaving no room for hindsight bias to occur (Fischhoff \& Beyth, 1975).

Participants' predictions at Part 1 tended to reflect their desired outcomes. Such desirability bias (Fischer \& Budescu, 1995) suggests that predictions were, at least partly, motivation-driven. Nevertheless, there was little direct evidence that the detected motivational 
HOW WILL THE OCCUPATION END?

processing led to retroactive pessimism when recalling predictions. In particular, the hindsight bias indices for the prediction that the occupation would achieve its goal and the government would resign were significantly associated with neither disappointment with the outcome of the occupation nor support for the occupation. Four out of six associations were close to zero or negative, and the respective Bayes factors favored the null over the expected effect. It is worth emphasizing that hindsight bias was detected for the 'government resigned, occupation ended' prediction at three months. Hence, the lack of support for retroactive pessimism cannot be explained away by a lack of hindsight bias in this case. ${ }^{7}$ More generally, the lack of confirmatory evidence in this study is consistent with a previous failure to support retroactive pessimism also using a memory design (Pezzo \& Beckstead, 2008). Still, two out of six associations were in the expected direction and their corresponding Bayes factors favored neither the expected effect nor the null hypothesis of no effect (Table 5). It is thus possible that the present study did not have sufficient statistical power to detect a genuine effect, albeit smaller than the one reported using reassessment (Tykocinski et al., 2002; Wann et al., 2008). Further research needs to investigate more robustly whether retroactive pessimism can be detected with a memory design and thus be called justifiably a type of hindsight bias.

Both the authors of the original effect (Tykocinski, 2001; Tykocinski et al., 2002) and subsequent research have underscored the difference between retroactive pessimism and "classic" hindsight bias. Tykocinski et al. (2002) stated that the effect is a result of motivational

7 One might object that this logic does not hold for the same option in the final-outcome prediction, as its hindsight bias index was not significant. However, absence of hindsight bias does not, in principle, preclude presence of retroactive pessimism. This can happen if hindsight bias is positive in high but negative (i.e., reversed) in low levels of disappointment. Although the reversed and the positive values cancel out each other, resulting in absence of overall HSB, the relationship between HSB and disappointment can still be positive. 
HOW WILL THE OCCUPATION END?

rather than cognitive processes. The multiple components view of hindsight bias (Blank et al., 2008) subsequently classified retroactive pessimism as an instance of "inevitability impressions", to be distinguished from "memory distortions". Both approaches, however, categorized retroactive pessimism as a subtype of hindsight bias at the expense of expanding, potentially overstretching, the original definition of hindsight bias. The resulting category quite probably contains heterogeneous effects, some of which are not necessarily biases. Further use of a more conservative definition and methods (Fischhoff \& Beyth, 1975) might ultimately help confirm the status of retroactive pessimism as a genuine type of hindsight bias or, alternatively, disassociate it from a category it does not belong to.

The study has several limitations. The most obvious is its small sample size, which adds substantial uncertainty to its conclusions. We used an approach of optimizing the Type I error level to obtain an acceptable level of statistical power (Mudge et al., 2012, 2017) and assessed the relative evidence in favor of the alternative versus the null hypothesis using Bayes factors. Still, this is not a substitute for a larger sample. Achieving the latter is problematic in the exploration of unusual real-world events that are not only time-limited but also present logistical challenges to preparing materials and recruiting participants. While the specificity of the context prevents replication with a larger sample, aspects of the approach and incompletely answered questions are worth pursuing in future research.

Another limitation relates to our choice of specific events/outcomes. In compiling the items, we tried to think of events that would be salient enough to be noticed by participants. We further aimed to include events that would naturally evoke attributions of responsibility (see footnote 1). This restricted the set to a handful of negative events (from an occupation supporter's perspective). Furthermore, these events were, as it turned out, correctly deemed 
HOW WILL THE OCCUPATION END?

unlikely by the majority of participants. Relying on the occurrence of unlikely negative events to test our predictions might have been overly optimistic, in hindsight. Future studies can try to derive predictions that could be tested over a wider variety of events in terms of likelihood and valence.

In spite of these limitations, this is a unique study in the context of research on hindsight bias for real-world events, itself a rather weak strand of hindsight bias research (Guilbault et al., 2004; Pezzo \& Beckstead, 2008). To our knowledge, no other published study explores an event which has, on the one hand, profound personal and daily consequences for a core role of its participants (their ability to attend university) and, on the other, potentially far-reaching political and historical impact for the country they live in. While, with the benefit of hindsight, neither the personal impact of the event was long-lasting, nor the direction of the country politics changed, with much of the status-quo soon restored, the latter was deeply shaken at the time of the study. In comparison, most published real-world research on hindsight bias concerns either regularly occurring events (e.g., outcomes of political elections or sport games: Blank et al., 2003; Blank \& Nestler, 2006; Pezzo, 2003; Roese \& Maniar, 1997) or events too far removed from participants' daily lives (e.g. the outcomes of the US President's visit to China and the USSR from the perspective of Israeli students, Fischhoff \& Beyth, 1975). The two studies concerning extraordinary events of which we are aware-one about the verdict of O. J. Simpson criminal trial (Bryant \& Brockway, 1997) and the other about US President Clinton's Impeachment Verdict (Bryant \& Guilbault, 2002)—had sample sizes comparable to ours. This may be indicative of the challenges of collecting data for extraordinary events. Despite its limited sample size, a study of this type presents a valuable record of the attitudes, thoughts, and feelings of people deeply invested in a unique real-world event. It may also advance research in the field of 
HOW WILL THE OCCUPATION END?

hindsight bias through informing the better planning of future research in light of its strengths and weaknesses.

In summary, this was a small-scale study that adds to the limited evidence and methodological toolbox concerning hindsight bias in the case of real-world events. In particular, it proposed using a recall/reconstruct measure to test for retroactive pessimism which has, so far, been largely tested through reassessment. Although we cannot make strong claims on the basis of the present evidence, we would also call for greater attention to the association between conceptualizations and methods used to study hindsight bias. Such an association may impact the nature and size of the resulting findings, potentially leading to using the same term for inherently diverse phenomena. On the upside, we can look forward to intriguing developments in the study of hindsight bias, preferably more often around real-world events. 
HOW WILL THE OCCUPATION END?

\section{References}

Auguie, B. (2017). gridExtra: Miscellaneous functions for "Grid" graphics (2.3) [Computer software]. https://CRAN.R-project.org/package=gridExtra

Benjamini, Y., \& Hochberg, Y. (1995). Controlling the false discovery rate: A practical and powerful approach to multiple testing. Journal of the Royal Statistical Society: Series B (Methodological), 57(1), 289-300. https://doi.org/10.1111/j.2517-6161.1995.tb02031.x

Blank, H., Fischer, V., \& Erdfelder, E. (2003). Hindsight bias in political elections. Memory, 11(4/5), 491-504. https://doi.org/10.1080/09658210244000513

Blank, H., Musch, J., \& Pohl, R. F. (2007). Hindsight bias: On being wise after the event. Social Cognition, 25(1), 1-9. https://doi.org/10.1521/soco.2007.25.1.1

Blank, H., \& Nestler, S. (2006). Perceiving events as both inevitable and unforeseeable in hindsight: The Leipzig candidacy for the Olympics. British Journal of Social Psychology, 45(1), 149-160. https://doi.org/10.1348/014466605X52326

Blank, H., Nestler, S., von Collani, G., \& Fischer, V. (2008). How many hindsight biases are there? Cognition, 106(3), 1408-1440.

Bryant, F. B., \& Brockway, J. H. (1997). Hindsight bias in reaction to the verdict in the OJ Simpson criminal trial. Basic and Applied Social Psychology, 19(2), 225-241. https://doi.org/10.1207/s15324834basp1902_5

Bryant, F. B., \& Guilbault, R. L. (2002). "I Knew It All Along" Eventually: The Development of Hindsight Bias in Reaction to the Clinton Impeachment Verdict. Basic and Applied Social Psychology, 24(1), 27-41. https://doi.org/10.1207/S15324834BASP2401_3

Champely, S. (2018). pwr: Basic functions for power analysis (1.2-2) [Computer software]. https://CRAN.R-project.org/package=pwr 
HOW WILL THE OCCUPATION END?

Christensen-Szalanski, J. J., \& Willham, C. F. (1991). The hindsight bias: A meta-analysis. Organizational Behavior and Human Decision Processes, 48(1), 147-168. https://doi.org/10.1016/0749-5978(91)90010-Q

Conde, I. C., \& de Una Alvarez, J. (2016). sgof: Multiple hypothesis testing. https://CRAN.Rproject.org/package $=$ sgof

Fischer, I., \& Budescu, D. V. (1995). Desirability and hindsight biases in predicting results of a multi-party election. In J.-P. Caverni, M. Bar-Hillel, F. H. Barron, \& H. Jungerman (Eds.), Contributions to decision making (Vol. 1, pp. 193-211). Elsevier.

Fischhoff, B. (1975). Hindsight $\neq$ foresight: The effect of outcome knowledge on judgment under uncertainty. Journal of Experimental Psychology: Human Perception and Performance, 1(3), 288-299. https://doi.org/10.1037/0096-1523.1.3.288

Fischhoff, B., \& Beyth, R. (1975). I knew it would happen: Remembered probabilities of oncefuture things. Organizational Behavior and Human Performance, 13(1), 1-16. https://doi.org/10.1016/0030-5073(75)90002-1

Fischhoff, B., Gonzalez, R. M., Lerner, J. S., \& Small, D. A. (2012). Evolving judgments of terror risks: Foresight, hindsight, and emotion: A reanalysis. Journal of Experimental Psychology: Applied, 18(2), e1-e16. https://doi.org/10.1037/a0027959

Guilbault, R. L., Bryant, F. B., Brockway, J. H., \& Posavac, E. J. (2004). A Meta-Analysis of Research on Hindsight Bias. Basic \& Applied Social Psychology, 26(2/3), 103-117. https://doi.org/10.1080/01973533.2004.9646399

Haslam, N., \& Jayasinghe, N. (1995). Negative affect and hindsight bias. Journal of Behavioral Decision Making, 8(2), 127-135. https://doi.org/10.1002/bdm.3960080205 
HOW WILL THE OCCUPATION END?

Hastie, R., Schkade, D. A., \& Payne, J. W. (1999). Juror judgments in civil cases: Hindsight effects on judgments of liability for punitive damages. Law and Human Behavior, 23(5), 597-614. https://doi.org/10.1023/A:1022352330466

Hawkins, S. A., \& Hastie, R. (1990). Hindsight: Biased judgments of past events after the outcomes are known. Psychological Bulletin, 107(3), 311-327. https://doi.org/10.1037/0033-2909.107.3.311

Hoyt, A. D. R. \& W. T. (2018). MAd: Meta-Analysis with Mean Differences (0.8-2.1) [Computer software]. https://CRAN.R-project.org/package=MAd

Junes, T. (2013, November 12). Students Take Bulgaria's Protests to the Next Level. Can They Break the Political Stalemate? IWM. http://www.iwm.at/transit/transit-online/studentstake-bulgarias-protests-to-the-next-level-why-the-student-protests-could-break-thepolitical-stalemate/

Louie, T. A., Curren, M. T., \& Harich, K. R. (2000). "I knew we would win": Hindsight bias for favorable and unfavorable team decision outcomes. Journal of Applied Psychology, 85(2), 264-272. https://doi.org/10.1037/0021-9010.85.2.264

Ly, A., Verhagen, J., \& Wagenmakers, E.-J. (2016). Harold Jeffreys's default Bayes factor hypothesis tests: Explanation, extension, and application in psychology. Journal of Mathematical Psychology, 72, 19-32. https://doi.org/10.1016/j.jmp.2015.06.004

Morey, R. D., \& Rouder, J. N. (2011). Bayes factor approaches for testing interval null hypotheses. Psychological Methods, 16(4), 406-419. https://doi.org/10.1037/a0024377

Morey, R. D., Rouder, J. N., Jamil, T., Urbanek, S., Forner, K., \& Ly, A. (2018). BayesFactor: Computation of Bayes Factors for Common Designs (0.9.12-4.2) [Computer software]. https://CRAN.R-project.org/package=BayesFactor 
HOW WILL THE OCCUPATION END?

Mudge, J. F., Baker, L. F., Edge, C. B., \& Houlahan, J. E. (2012). Setting an optimal $\alpha$ that minimizes errors in null hypothesis significance tests. PloS One, 7(2), e32734. https://doi.org/10.1371/journal.pone.0032734

Mudge, J. F., Martyniuk, C. J., \& Houlahan, J. E. (2017). Optimal alpha reduces error rates in gene expression studies: A meta-analysis approach. BMC Bioinformatics, 18(1), 312. https://doi.org/10.1186/s12859-017-1728-3

Musch, J., \& Wagner, T. (2007). Did everybody know It all along? A review of individual differences in hindsight bias. Social Cognition, 25(1), 64-82. https://doi.org/10.1521/soco.2007.25.1.64

Pezzo, M. V. (2003). Surprise, defense, or making sense: What removes hindsight bias? Memory, 11(4-5), 421-441. https://doi.org/10.1080/09658210244000603

Pezzo, M. V., \& Beckstead, J. (2008). The effects of disappointment on hindsight bias for realworld outcomes. Applied Cognitive Psychology, 22(4), 491-506. https://doi.org/0.1002/acp.1377

Pohl, R. F. (2007). Ways to assess hindsight bias. Social Cognition, 25(1), 14-31. https://doi.org/10.1521/soco.2007.25.1.14

R Core Team. (2021). R: A language and environment for statistical computing. R Foundation for Statistical Computing. https://www.R-project.org/

Re, A. D. (2020). compute.es: Compute Effect Sizes (0.2-5) [Computer software]. https://CRAN.R-project.org/package=compute.es

Renner, B. (2003). Hindsight bias after receiving self-relevant health risk information: A motivational perspective. Memory, 11(4/5), 455-472. https://doi.org/10.1080/09658210244000531 
HOW WILL THE OCCUPATION END?

Revelle, W. (2020). psych: Procedures for psychological, psychometric, and personality research (1.9.12.31) [Computer software]. https://CRAN.R-project.org/package=psych

Roese, N. J., \& Maniar, S. D. (1997). Perceptions of purple: Counterfactual and hindsight judgments at Northwestern Wildcats football games. Personality and Social Psychology Bulletin, 23(12), 1245-1253. https://doi.org/10.1177/01461672972312002

Roese, N. J., \& Olson, J. M. (1996). Counterfactuals, causal attributions, and the hindsight bias: A conceptual integration. Journal of Experimental Social Psychology, 32(3), 197-227. https://doi.org/10.1006/jesp.1996.0010

Roese, N. J., \& Vohs, K. D. (2012). Hindsight bias. Perspectives on Psychological Science, 7(5), 411-426. https://doi.org/10.1177/1745691612454303

Rouder, J. N., Speckman, P. L., Sun, D., Morey, R. D., \& Iverson, G. (2009). Bayesian t tests for accepting and rejecting the null hypothesis. Psychonomic Bulletin \& Review, 16(2), 225237. https://doi.org/10.3758/PBR.16.2.225

Tykocinski, O. E. (2001). I never had a chance: Using hindsight tactics to mitigate disappointments. Personality and Social Psychology Bulletin, 27(3), 376-382. https://doi.org/10.1177/0146167201273011

Tykocinski, O. E., Pick, D., \& Kedmi, D. (2002). Retroactive pessimism: A different kind of hindsight bias. European Journal of Social Psychology, 32(4), 577-588. https://doi.org/10.1002/ejsp.120

Wann, D. L., Grieve, F. G., Waddill, P. J., \& Martin, J. (2008). Use of retroactive pessimism as a method of coping with identity threat: The impact of group identification. Group Processes \& Intergroup Relations, 11(4), 439-450. https://doi.org/10.1177/1368430208095399 
HOW WILL THE OCCUPATION END?

Wickham, H., \& RStudio. (2019). tidyverse: Easily Install and Load the "Tidyverse" (1.3.0)

[Computer software]. https://CRAN.R-project.org/package=tidyverse 